Int. J. Electrochem. Sci., 14 (2019) 2683 - 2692

International Journal of

ELECTROCHEMICAL

SCIENCE

WWW.electrochemsci.org

\title{
Corrosion behavior of AISI321 stainless steel in an ethylene glycol-water solution
}

Xiaoguang Zhang ${ }^{1}$, Xiang Liu ${ }^{2}$, Wenping Dong ${ }^{2}$, Endian $\mathrm{Fan}^{3}$, Ziheng Bai ${ }^{3}$, Gengkai $\mathrm{Hu}^{1}$, Pan $\mathrm{Yi}^{3}$, Kui Xiao ${ }^{3}$, Yunhua Huang,

${ }^{1}$ School of Aerospace Engineering, Beijing Institute of Technology, No.5 South Zhongguancun Street, Beijing 100081, China

${ }^{2}$ National key laboratory of human factors engineering, China astronaut research and training center, Beijing 100094, China

${ }^{3}$ Institute of Advanced Materials and Technology, University of Science and Technology Beijing, Beijing 100083, China.

*E-mail: huangyh@mater.ustb.edu.cn

doi: $10.20964 / 2019.03 .24$

Received: 19 July 2018 / Accepted: 12 January 2019 / Published: 7 February2019

The electrochemical corrosion behaviors of AISI321 stainless steel in a 36\% ethylene glycol-water solution are investigated by electrochemical impedance spectroscopy, Mott-Schottky analysis, electrochemical atomic force microscopy and X-ray photoelectron spectroscopy. The results indicated that the calculated donor density increased, as a result of an increasing passive film formation potential, suggesting that the passive film formed at high potential provided much better protection performance. The $n$-type semiconductor behavior was observed in the potential range from -0.15 to $0.45 \mathrm{~V}$ (vs. SCE), however p-type semiconductor behavior was observed in the potential range from 0.45 to $0.75 \mathrm{~V}$, and the carrier density decreased with the increasing potential during the passivation.

Keywords: AISI321 stainless steel; Corrosion; Mott-Schottky analysis; EIS; EC-AFM

\section{$\underline{\text { FULL TEXT }}$}

(C) 2019 The Authors. Published by ESG (www.electrochemsci.org). This article is an open access article distributed under the terms and conditions of the Creative Commons Attribution license (http://creativecommons.org/licenses/by/4.0/). 